\title{
Genotypic Differences in the Length-Diameter Relationship of Branches of One-year-old Peach and Nectarine Trees
}

\author{
Jocelyne Kervella ${ }^{1}$, Loïc Pagès ${ }^{2}$, and Michel Génard \\ Institut National de la Recherche Agronomique, Domaine Saint-Paul, 84143 Montfavet cedex, France
}

\begin{abstract}
Additional index words. Prunus persica, mechanical resistance, hydraulic conductivity, selection, breeding, genetics, fruit tree

Abstract. Genotypic variations in the length-diameter relationship of branches among peach and nectarine [Prunus persica (L.) Batsch.] cultivars were investigated. The length and basal diameter of all undamaged first-order shoots from 1-year-old trees of 14 cultivars and one accession were measured. Statistical analysis of the allometric relationship between length and basal diameter of shoots provided evidence of genotypic differences for that relationship, although the diameter of very short shoots did not differ between genotypes. A gradient existed from 'Armking' with thin shoots $(9 \mathrm{~mm}$ in diameter for 85.5-cm-long shoots) to 'Flavorcrest' with thick shoots (16.4 mm in diameter for 85.5-cm-long shoots). Early selection for shoot thickness should be possible in breeding programs. The likely consequences of observed shoot thickness variations on the mechanical and hydraulic properties of shoots are discussed.
\end{abstract}

Shoot thickness is likely to be an important feature of fruit tree habit. It has been shown that the mechanical (Cannell and Morgan, 1987; Niklas, 1992; Upadhyaya et al., 1987) and conductivity (Cochard, 1992; Tyree et al., 1991) properties of shoots depend on shoot thickness. These properties have important consequences for fruit production. Shoots with excessive fruit load bend or even break in the orchard. Pendant shoots generally produce lowerquality fruit (Tusting et al., 1988). Mechanical resistance therefore limits the weight and quality of the fruit a branch can bear. Hydraulic conductivity has consequences on the water status of leaves and therefore on $\mathrm{CO}_{2}$ assimilation. It may also influence fruit quality. The findings of Génard and Bruchou (1992) that fruit sucrose concentration was positively related to diameter support this hypothesis.

There are some reports on the effects of pruning on shoot thickness (Brown and Harris, 1958; Rom and Ferree, 1984, 1985), but genotypic variations of shoot thickness have received little attention. Recent work describing genotypic variations in peach tree habit has focussed on major differences between dwarf, compact, semidwarf, pillar, spur, and standard growth types (Scorza, 1984, 1987; Scorza et al., 1986, 1989). The aim of that work was to improve the understanding of the functioning of trees belonging to each growth type (Scorza et al., 1986) and to provide a method to classify new genotypes according to these growth habit types for breeding purposes (Scorza, 1984).

In France, medium-density production systems with standard cultivars seem to be more suitable than high-density systems using reduced-size varieties. Fruit growers have observed that within a standard growth type, differences in growth characteristics also exist. Our objective is to describe these differences. We report here a study of the differences among standard genotypes for shoot thickness, evaluated by an allometric relationship between length and basal diameter of shoots.

\footnotetext{
Received for publication 24 May 1993. Accepted for publication 28 Sept. 1993 This work was supported by INRA AIP Agrophysiologie des arbres fruitiers. We thank T. Pascal and J. Aymard for their help in choosing the genotypes studied and C. Bruchou for his valuable mathematical advice. The cost of publishing this paper was defrayed in part by the payment of page charges. Under postal regulations, this paper therefore must be hereby marked advertisement solely to indicate this fact. ${ }^{1}$ Station de Recherches Fruitières Méditerranéennes.

${ }^{2}$ Laboratoire d'Agronomie.
}

\section{Material and Methods}

Fourteen cultivars (Alexandra, Armking, Fantasia, Fairlane, Flavorcrest, Flavortop, O'Henry, Redcal, Red Diamond, Redwing, Royal Glory, Silver Gem, Springlady, Snowqueen) and one accession (M1339) were studied. Two clones of 'Springlady' were observed. Five trees of each genotype grafted on GF 305 rootstock in May 1990 were grown in 50-liter pots containing a peat-sand mixture. They were irrigated with a complete nutrient solution and left unpruned.

Let the main shoot, issuing from the meristem of the grafted bud, be the zero-order shoot, shoots directly inserted on the main shoot be first-order shoots, and so on. In November 1990, after leaf fall, trees were branched to the second order. The length and basal (at $\approx 1 \mathrm{~cm}$ from the insertion point) overbark diameter of all undamaged first-order shoots was measured.

Two dimensions - $\mathrm{x}$ and $\mathrm{y}-\mathrm{of}$ an organ or of an organism may often be related with a good approximation by the nonlinear equation $y=\alpha_{0}+\alpha_{1} x^{\beta}$, which is known as an allometric relationship (Causton and Venus, 1981). The nonlinear model $\mathrm{D}=\alpha_{0}+$ $\alpha_{1} \mathrm{~L}_{\mathrm{i}}$-where $\mathrm{D}(\mathrm{mm})$ is basal shoot diameter, $\mathrm{L}(\mathrm{cm})$ is shoot length, subscript $i$ denotes the genotype ( $i=1 . .16)$, and $\alpha_{0}, \alpha_{1}$, and $\beta$ are the parameters of the model - was therefore used to describe the length-basal diameter relationship of shoots. With such a model, the way to assess differences between genotypes is to follow a procedure testing whether parameters $\alpha_{0}, \alpha_{1}$, and $\beta$ are constant or depend on genotype. This is done by considering a hierarchy of nested models. Such a hierarchy is a set of submodels in which each submodel is a special case of the previous one; i.e., one or several parameters dependent on the genotype in one submodel are assumed to be constant in the next one. If, for example, $\alpha_{0}$ is assumed to be constant, a single value is estimated for all the genotypes. If it depends on the genotype, 16 values $\alpha_{0 i}$, one for each genotype $(i=1 . .16)$, are estimated.

We considered five submodels. In submodel 5, parameters $\alpha_{0}, \alpha_{1}$, and $\beta$ were assumed to be constant, whatever the genotype. In submodels 3 and $4, \alpha_{1}$ and $\beta$ could respectively depend on the genotype. In submodel $2, \alpha_{1}$ and $\beta$ could both depend on the genotype and only $\alpha_{0}$ was assumed to be equal, whatever the genotype. In model 1 , all three parameters could depend on the genotype. Hence, submodels 1, 2, 3, and 5 on one hand and submodels 1,2, 4, and 5 on the other formed a hierarchy of nested submodels. 
Table 1. Statistical study of the genotypic variations for the allometric relationship between shoot length and shoot basal diameter, number of parameters (np), degrees of freedom (df), residual sum of square (RSS), and comparisons between models 1, 2, 3, 4 , and 5 .

\begin{tabular}{lccccccc}
\hline \hline Model & $\mathrm{np}^{\mathrm{z}}$ & $\mathrm{df}$ & $\mathrm{RSS}$ & Comparison & Hypothesis & MLR $^{\mathrm{y}}$ & $P$ \\
\hline 1 & 48 & 1407 & 750.90 & & & & \\
2 & 33 & 1422 & 754.27 & Model 2/model 1 & $\alpha_{0}$ constant & 10.96 & 0.76 \\
3 & 18 & 1437 & 803.40 & Model 3/model 2 & $\alpha_{1}$ constant & 91.82 & $<0.001$ \\
4 & 18 & 1437 & 789.40 & Model 4/model 2 & $\beta$ constant & 66.24 & $<0.001$ \\
5 & 3 & 1452 & 1515.34 & Model 5/model 3 & $\alpha_{1}$ and $\beta$ constant & 923.26 & $<0.0001$ \\
\hline
\end{tabular}

${ }_{\mathrm{z}} \mathrm{p}=$ Total number of different values estimated for parameters $\alpha_{0}, \alpha_{1}$, and $\beta$.

${ }^{\mathrm{y}} \mathrm{MLR}=$ maximum-likelihood ratio for the comparison.

Each submodel was fitted to the data using the least-square estimators [procedure nls of S software (Chambers and Hastie, 1992)]. The residuals were normally distributed for each submodel considered. The equality of parameters was tested by comparing one submodel to the previous one with a maximum-likelihood ratio (MLR) test (Huet et al., 1992).

The use of principal component (PC) analysis for classifying genotypes according to their similarities has been stressed by Iezzoni and Pritts (1991). Very often, however, similarity between genotypes for the relationship modeled cannot be inferred from similarity of the estimated values of the model parameters, especially when these estimated values are correlated. To overcome this difficulty, one can use PC analysis on a data set such that each row corresponds to one of the genotypes studied and each column is the fitted value of the dependent variable (diameter, in this case) for a specified value of the independent variables (length, in this case). This fitted value is computed using the estimated values of the model parameters. With such a data set, the distance between two genotypes in the PC analysis is an increasing function of the area lying between the curves fitted for those genotypes. In our data set, there were 18 variables corresponding to diameter values calculated for length values evenly spaced every $5 \mathrm{~cm}$ from 0.5 to $85.5 \mathrm{~cm}$.

\section{Results}

Degrees of freedom and MLRs for each submodel studied are summarized in Table 1 with the MLR comparisons. These comparisons demonstrate that varietal differences exist in the lengthbasal diameter relationships of first-order shoots, since model 5 is significantly far worse than any other model $(P<0.0001)$. Model 3 and model 4 are both significantly better than model 5 , indicating that at least one of the parameters $\left(\alpha_{1}\right.$ or $\left.\beta\right)$ depends on genotype. Model 2 is significantly better $(P<0.001)$ than either model 3 or model 4 but not significantly worse $(P=0.76)$ than model 1 . Thus, no significant differences are found between genotypes for parameter $\alpha_{0}\left(\alpha_{0}=2.76 \mathrm{~mm}\right)$, but both $\alpha_{1}$ and $\beta$ depend on genotype. The estimated values of $\alpha_{1 \mathrm{i}}$ and $\beta_{\mathrm{i}}$ for each genotype are reported in Table 2 . The estimators of $\alpha$ and $\beta$ for each genotype were highly correlated (correlation coefficient $>0.98$ ).

In the $\mathrm{PC}$ analysis, the first $\mathrm{PC}\left(\mathrm{PC}_{1}\right)$ accounted for $93 \%$ of the variation in dataset and, therefore, was the only PC studied. It was highly correlated with the fitted diameters for the highest length values. Hence, $\mathrm{PC}_{1}$ scores ordered genotypes mainly according to the diameters of long branches. The $\mathrm{PC}_{1}$ scores of the 15 genotypes studied are shown in Fig. 1. Rather than clusters, there was a gradient of genotypes, from 'Armking' with an extreme negative score for $\mathrm{PC}_{1}$, producing thin long shoots $(9 \mathrm{~mm}$ in diameter for $85.5-\mathrm{cm}$-long shoots) to 'Flavorcrest' producing thick long shoots (16 $\mathrm{mm}$ in diameter for $85.5-\mathrm{cm}$-long shoots ). The scores of the
Table 2. Estimated values and SEs of parameters $\alpha_{1}$ and $\beta$ for each genotype.

\begin{tabular}{lccccc}
\hline \hline & \multicolumn{3}{c}{$\alpha_{1}$} & & $\beta$ \\
\cline { 2 - 3 } \cline { 5 - 6 } Genotype & Value & SE & & Value & SE \\
\hline Alexandra & 0.013 & 0.003 & & 1.502 & 0.062 \\
Armking & 0.004 & 0.001 & & 1.647 & 0.065 \\
Fantasia & 0.028 & 0.007 & & 1.337 & 0.063 \\
Flavorcrest & 0.026 & 0.006 & & 1.405 & 0.056 \\
Fairlane & 0.016 & 0.004 & & 1.509 & 0.066 \\
Flavortop & 0.029 & 0.007 & & 1.331 & 0.058 \\
M1339 & 0.036 & 0.024 & 1.212 & 0.182 \\
O'Henry & 0.017 & 0.005 & 1.465 & 0.075 \\
Redcal & 0.066 & 0.019 & 1.088 & 0.076 \\
Red Diamond & 0.029 & 0.007 & & 1.326 & 0.056 \\
Redwing & 0.040 & 0.010 & 1.216 & 0.061 \\
Royal Glory & 0.022 & 0.004 & 1.407 & 0.048 \\
Springlady & 0.022 & 0.006 & 1.374 & 0.066 \\
Silver Gem & 0.033 & 0.008 & 1.335 & 0.062 \\
Springlady & 0.019 & 0.009 & 1.410 & 0.114 \\
Snowqueen & 0.042 & 0.013 & 1.222 & 0.079 \\
\hline
\end{tabular}

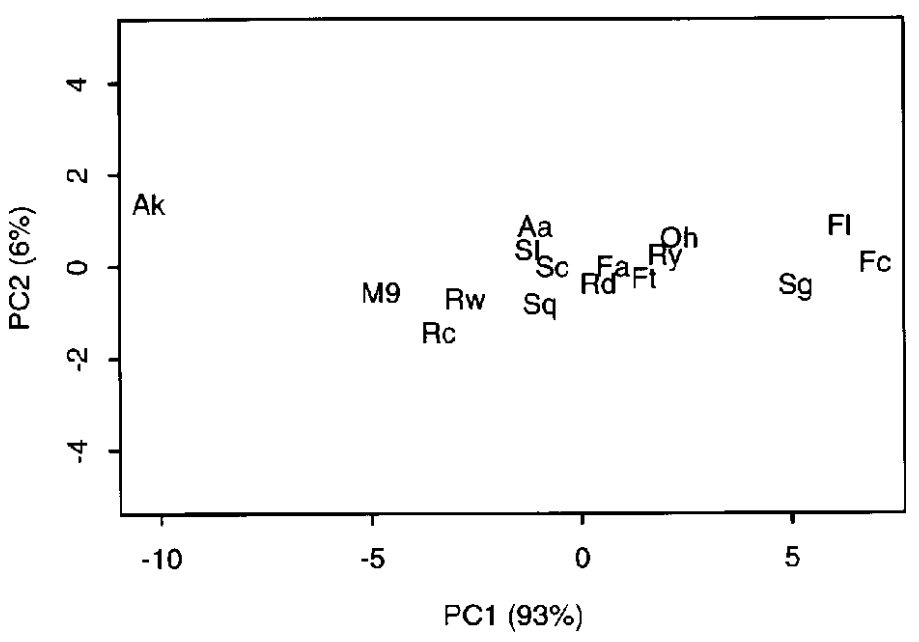

Fig. 1. Genotype scores for the first two components of $\mathrm{PC}$ analysis. $\mathrm{PC}_{1}$ ranks genotypes according to long shoot thickness. Aa = 'Alexandra', Ak = 'Armking', $\mathrm{Fa}=$ 'Fantasia', $\mathrm{Fl}=$ 'Fairlane', $\mathrm{Fc}=$ 'Flavorcrest', $\mathrm{Ft}=$ 'Flavortop', $\mathrm{M} 9=$ 'M1339', Oh = 'O'Henry', Rc = 'Redcal', Rd = 'Red Diamond', Rw = 'Redwing', $\mathrm{Ry}=$ 'Royal Glory', Sg = 'Silver Gem', Sc and Sl = 'Springlady', Sq = 'Snowqueen'.

two 'Springlady' clones ( $\mathrm{Sc}$ and $\mathrm{Sl}$ ) were similar. The continuous trend from thin to thick long branches is also apparent in Fig. 2, in which the fitted allometric curve and the observed values are plotted for nine genotypes evenly distributed along $\mathrm{PC}_{1}$. 


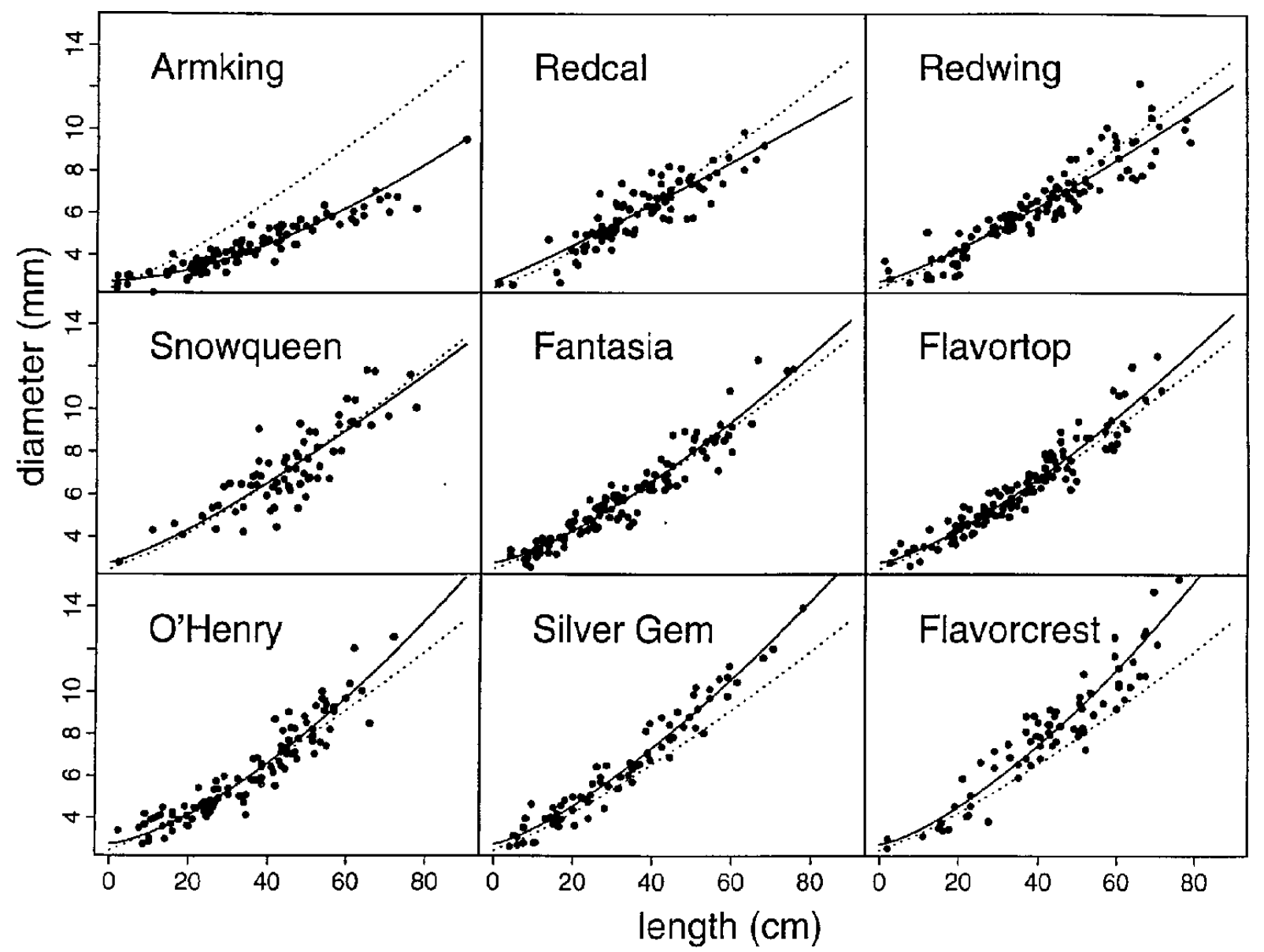

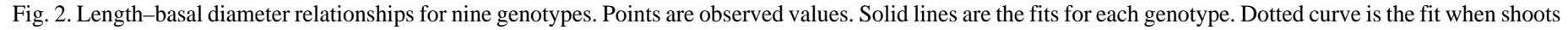
from all genotypes are bulked (model 5 in text).

\section{Discussion}

In our model, $\alpha_{0}$ is the value toward which the basal diameter of shoots tends when shorter and shorter shoots are considered. There are no significant differences among genotypes for $\alpha_{0}$ values. The initial basal diameter of shoots, just after their emergence, is the same, whatever the genotype. Conversely, varietal differences in branch diameter are apparent for longer branches. They must therefore result from differences in the relationship between length growth and diameter growth. Genotypic variations in dry-matter distribution between length and diameter growth may hold true everywhere in the tree at any time during the growing season. However, on first-year peach trees, first-order shoots appear for the whole growing season in the axils of unfolding leaves. Consequently, the longest shoots were generally the basal and oldest ones. Two other hypotheses must therefore be considered. First, the variations in length-diameter relationships observed may also result from variations in dry-matter distribution between basal and distal branches. Large-diameter long shoots could be an expression of tree basitony rather than of branch thickness per se. Second, there may be genotypic differences in the seasonal pattern of diameter growth. Periodically measuring shoot length and diameter during the growing season would help to test these hypotheses.

Using PC analysis, we ranked the genotypes studied according to their long-shoot thickness. The ranking from 'Armking' with the thinnest long shoots to 'Flavorcrest' with the thickest ones agreed with growers' empirical knowledge of these genotypes.
Early selection for shoot thickness could be practiced on 1-yearold trees in good growing conditions, although caution must be taken as underlined by previous remarks about the possible origins of the variations observed. Breeders must have indirectly selected peach trees for thick shoots when selecting for fruit size and quality, since shoots of GF 305 Prunus persica rootstock and shoots of related wild species such as $P$. davidiana and $P$. kansuensis appear visually thinner than 'Armking' shoots. The great differences between those genotypes, unselected for fruit characteristics, and present cultivars and the continuous trend observed among cultivars suggest polygenic inheritance of the trait.

Variations of length-diameter relationships may have important effects on mechanical and hydraulic properties of branches, which in turn may have important horticultural consequences, as noted above. According to the theory for static mechanics of cantilever beams, mechanical resistance to loading, which determines the heaviest fruit weight that a shoot can bear, depends on Young's modulus of the shoot and on the fourth power of shoot diameter (Morgan and Cannell, 1987; Upadhyaya et al. 1987). Variations in Young's modulus have been investigated. According to Upadhyaya et al. (1987), Young's modulus varies along apple limbs. These variations result from differences in turgor pressure of living cells and in tissue composition (Niklas, 1992; Upadhyaya et al., 1987), especially in the bark/wood ratio (Cannell and Morgan, 1987). Genotypic differences for such characteristics may occur. However, among 1-year old shoots, genotypic variations in Young's modulus due to tissue composition are likely to be smaller than those observed by Cannell and Morgan (1987) 
when comparing trunks and branches of different species, which were in a 1:10 ratio. Therefore, diameter variations could have greater importance in the mechanical resistance of shoots. Indeed, the ratio between the fourth power of the expected diameter ( 9 and $16.4 \mathrm{~mm}$, respectively) of 85.5-cm-long shoots for 'Flavorcrest' and 'Armking' equals 11. Predominance of diameter variations compared to Young's modulus variations on the stiffness of apple limb segments has been observed experimentally by Upadhyaya et al. (1987).

Variation in shoot diameter could also be a major source of hydraulic conductivity variation. Hydraulic properties of shoots have also been shown to be closely related to shoot diameter in species as different as Schefflera morototoni, Acer saccharum, Thuja occidentalis (Tyree et al., 1991), and Abies spp., Pinus spp., and Picea spp. (Cochard, 1992). In all cases, after log transformation, shoot hydraulic conductivity (expressed per length unit) increased linearly with shoot diameter. Close relationships were observed, even for wide ranges of diameter in studies involving genetically different trees (Tyree et al., 1991). Obviously, genetic differences exist in the relationship between shoot diameter and shoot hydraulic conductivity, since a different relationship is found for Schefflera morototoni and Thuja occidentalis, for example. However, the difference in hydraulic conductivity between 9- and 16.4-mm-diameter shoots belonging to the same species is of the same magnitude as the difference in the hydraulic conductivity of two shoots with equal diameter and belonging to each of those two very different species. The slope is always $>2$, indicating that hydraulic conductivity increased faster than shoot crosssectional area (Tyree et al., 1991).

To complement our results, additional information on varietal variations in shoot taper and shoot tissue composition would be useful. According to the Huber value theory (Zimmermann, 1983), shoot diameter is related to distal foliage area. It would be worth studying if the relationship between shoot diameter and shoot foliage area is more stable than the length-basal diameter relationship and if genotypic differences in foliage area account for genotypic differences in the length-basal diameter relationship.

The present study demonstrated that evidence for genotypic variations in the length-basal diameter relationship can be provided by studying 1-year old trees. The range of diameter values observed for long shoots shows that such variations are likely to greatly influence the mechanical resistance and hydraulic conductivity of shoots.

\section{Literature Cited}

Brown, D.S. and R.W. Harris. 1958. Summer pruning trees of early maturing peach varieties. Proc. Amer. Soc. Hort. Sci. 72:79-84.

Cannell, M.G.R. and J. Morgan. 1987. Young's modulus of sections of living branches and tree trunks. Tree Physiol. 3:355-364.

Causton, D.R. and J.C. Venus. 1981. The biometry of plant growth. Edward Arnold, London.

Chambers, J.M. and T.J. Hastie. 1992. Statistical models in S. Wadsworth \& Brooks, Pacific Grove, Calif.

Cochard, H. 1992. Vulnerability of several conifers to air embolism. Tree Physiol. 11:73-83.

Génard, M. and C. Bruchou. 1992. Multivariate analysis of within-tree factors accounting for the variation of peach fruit quality. Scientia Hort. 52:37-51.

Huet, S., E. Jolivet, and A. Messéan. 1992. La régression non-linéaire. Méthodes et applications en biologie. INRA, Paris.

Iezzoni, A.F. and M.P. Pritts. 1991. Application of principal component analysis to horticultural research. HortScience 26:334-338.

Morgan, J. and M.G.R. Cannell. 1987. Structural analysis of tree trunks and branches: Tapered cantilever beams subject to large deflections under complex loading. Tree Physiol. 3:365-374.

Niklas, K.J. 1992. Voigt and Reuss models for predicting changes in Young's modulus of dehydrating plant organs. Ann. Bot. 70:347-355.

Rom, C.R. and D.C. Ferree. 1984. The influence of summer pruning current-season shoots on growth, floral bud development, and winter injury of mature peach trees. HortScience 19:543-545.

Rom, C.R. and D.C. Ferree. 1985. Time and severity of summer pruning influences on young peach tree net photosynthesis, transpiration, and dry weight distribution. J. Amer. Soc. Hort. Sci. 110:455-461.

Scorza, R. 1984. Characterization of four distinct peach tree growth types. J. Amer. Soc. Hort. Sci. 109:455-457.

Scorza R., 1987. Identification and analysis of spur growth in peach (Prunus persica L. Batsch). J. Hort. Sci. 62:449-455.

Scorza R., G.W. Lightner, and A. Liverani. 1989. The pillar peach tree and growth habit analysis of compact $\times$ pillar progeny. J. Amer. Soc. Hort. Sci. 114:991-995.

Scorza, R., L. Zailong, G.W. Lightner, and L.E. Gilreath. 1986. Dry matter distribution and responses to pruning within a population of standard, semidwarf, compact and dwarf peach seedlings. J. Amer. Soc. Hort. Sci. 111:541-545.

Tusting, D.S., P.M. Hirst, and I.J. Warrington. 1988. Influence of orientation and position of fruiting laterals on canopy light penetration, yield, and fruit quality of ‘Granny Smith' apple. J. Amer. Soc. Hort. Sci. 113:693-699.

Tyree, M.T., D.A. Snyderman, T.R. Wilmot, and J.L. Machado. 1991. Water relations and hydraulic architecture of a tropical tree (Schefflera morototoni). Data, models, and a comparison with two temperate species (Acer saccharum and Thuja occidentalis). Plant Physiol. 96:1105-1113.

Upadhyaya, S.K., J.R. Cooke, and R.H. Rand. 1987. Variation in Young's modulus along apple limbs. Trans. Amer. Soc. Agr. Eng. 30:1501-1505.

Zimmermann, M.H. 1983. Xylem structure and the ascent of sap. Springer-Verlag, Berlin. 